\title{
The shipboard Beirut terrorist bombing experience: a historical account and recommendations for preparedness in events of mass neurological injuries
}

\author{
*Zachary S. Hubbard, MD, MPH, ${ }^{1}$ Fraser Henderson Jr., MD, ${ }^{1}$ Rocco A. Armonda, MD, ${ }^{2}$ \\ Alejandro M. Spiotta, MD, ${ }^{1}$ Robert Rosenbaum, MD, ${ }^{3}$ and Fraser Henderson Sr., MD ${ }^{3}$ \\ ${ }^{1}$ Department of Neurosurgery, The Medical University of South Carolina, Charleston, South Carolina; ${ }^{2}$ Department of \\ Neurosurgery, MedStar Georgetown University Hospital and Washington Hospital Center, Washington, DC; and ${ }^{3}$ The \\ Metropolitan Neurosurgery Group, Bethesda, Maryland
}

On a Sunday morning at 06:22 on October 23, 1983, in Beirut, Lebanon, a semitrailer filled with TNT sped through the guarded barrier into the ground floor of the Civilian Aviation Authority and exploded, killing and wounding US Marines from the 1st Battalion 8th Regiment (2nd Division), as well as the battalion surgeon and deployed corpsmen. The truck bomb explosion, estimated to be the equivalent of $21,000 \mathrm{lbs}$ of TNT, and regarded as the largest nonnuclear explosion since World War II, caused what was then the most lethal single-day death toll for the US Marine Corps since the Battle of Iwo Jima in World War II. Considerable neurological injury resulted from the bombing. Of the 112 survivors, 37 had head injuries, 2 had spinal cord injuries, and 9 had peripheral nerve injuries. Concussion, scalp laceration, and skull fracture were the most common cranial injuries.

Within minutes of the explosion, the Commander Task Force 61/62 Mass Casualty Plan was implemented by personnel aboard the USS Iwo Jima. The wounded were triaged according to standard protocol at the time. Senator Humphreys, chairman of the Preparedness Committee and a corpsman in the Korean War, commented that he had never seen such a well-executed evolution. This was the result of meticulous preparation that included training not only of the medical personnel but also of volunteers from the ship's company, frequent drilling with other shipboard units, coordination of resources throughout the ship, the presence of a meticulous senior enlisted man who carefully registered each of the wounded, the presence of trained security forces, and a drilled and functioning communication system.

Viewed through the lens of a neurosurgeon, the 1983 bombings and mass casualty event impart important lessons in preparedness. Medical personnel should be trained specifically to handle the kinds of injuries anticipated and should rehearse the mass casualty event on a regular basis using mock-up patients. Neurosurgery staff should participate in training and planning for events alongside other clinicians. Training of nurses, corpsmen, and also nonmedical personnel is essential. In a large-scale evolution, nonmedical personnel may monitor vital signs, work as scribes or stretcher bearers, and run messages. It is incumbent upon medical providers and neurosurgeons in particular to be aware of the potential for mass casualty events and to make necessary preparations.

https://thejns.org/doi/abs/10.3171/2018.9.FOCUS18390

KEYWORDS mass casualty; triage; Beirut bombing

Thou must be like a promontory of the sea, against which, though the waves beat continually, yet it both itself stands, and about it are those swelling waves stilled and quieted.

$$
\text { - Marcus Aurelius }{ }^{16}
$$

Despite numerous and deadly modern global conflicts, the domestic North American neurosurgeon has been for- tunate to avoid frequent experience with mass casualty. Nevertheless, preparedness remains vital and neurosurgeons must be aware of the potential for mass casualty. This report relates the authors' combined experiences gathered during overseas deployments in Lebanon, the Persian Gulf, Iraq, and Afghanistan for the purpose of fostering further discussion on casualty preparedness. The

* Z.S.H. and F.H. Jr. contributed equally to this work. 
specific neurological injuries encountered in Beirut, as well as the surgical lessons, have been well documented in prior reports..$^{10,11,19}$

We therefore present for the first time the preparations, triage, and perioperative shipboard experience, as well as a review of neurosurgical considerations for mass casualty preparedness, gleaned from the lessons learned there. As leaders in medicine, neurosurgeons may be called upon not only to act surgically in the operating theater but also to organize, lead, and participate in readiness drills and planning.

A complete record of the neurological injuries suffered has been reported, attributing a relatively low incidence of delayed death among immediate survivors of $6.3 \%$ to an excellent triage and evacuation system. ${ }^{19}$

\section{The Beirut Terrorist Bombing}

On a Sunday morning at 06:22 on October 23, 1983, in Beirut, Lebanon, a semitrailer filled with TNT sped through the guarded barrier into the ground floor of the Civilian Aviation Authority and exploded, killing and wounding Marines from the 1st Battalion 8th Regiment (2nd Division), as well as the battalion surgeon and deployed corpsmen. The truck bomb explosion, estimated to be the equivalent of $21,000 \mathrm{lbs}$ of TNT, and regarded as the largest nonnuclear explosion since World War II, caused the most lethal single-day death toll for the US Marine Corps since the Battle of Iwo Jima in World War II (Fig. 1). ${ }^{10}$

The Aviation Authority building, regarded as the only "safe haven" from the constant sniper and small artillery activity, was used as the battalion headquarters for the US Marines, deployed as part of the Multi-National Peace Keeping Force, sponsored by the United Nations. The Marines were operating under the peacetime rules of engagement to oversee the safe evacuation of Palestinian refugees. The Islamic Jihad, sponsored by Iran, claimed responsibility for this catastrophic event, which resulted in 241 deaths and approximately 112 wounded in action.

Of the survivors, $48(42.9 \%)$ suffered neurological injury as a result of the bombing: 37 (33\%) had head injuries, $9(8 \%)$ had peripheral nerve injuries, and $2(1.8 \%)$ had spinal cord injuries. ${ }^{19}$ Concussion, scalp laceration, and skull fracture were the most common cranial injuries. As mentioned, spine and spinal cord injury occurred in 2 survivors, but these injuries were much more common in the fatality group. There were 9 total peripheral nerve cases, all of which were in the immediate survivors. ${ }^{19}$ This defines a scenario in which the number of casualties overwhelms those available for neurosurgical care. Therefore, a definitive plan must be established in which resources can be efficiently allocated and information quickly disseminated.

\section{Commander Task Force 61/62 Mass Casualty Plan}

Within minutes of the explosion, the Commander Task Force (CTF) 61/62 Mass Casualty Plan was implemented. By 06:30, the Mass Casualty Plan was implemented by personnel aboard the USS Iwo Jima. The remaining medi-

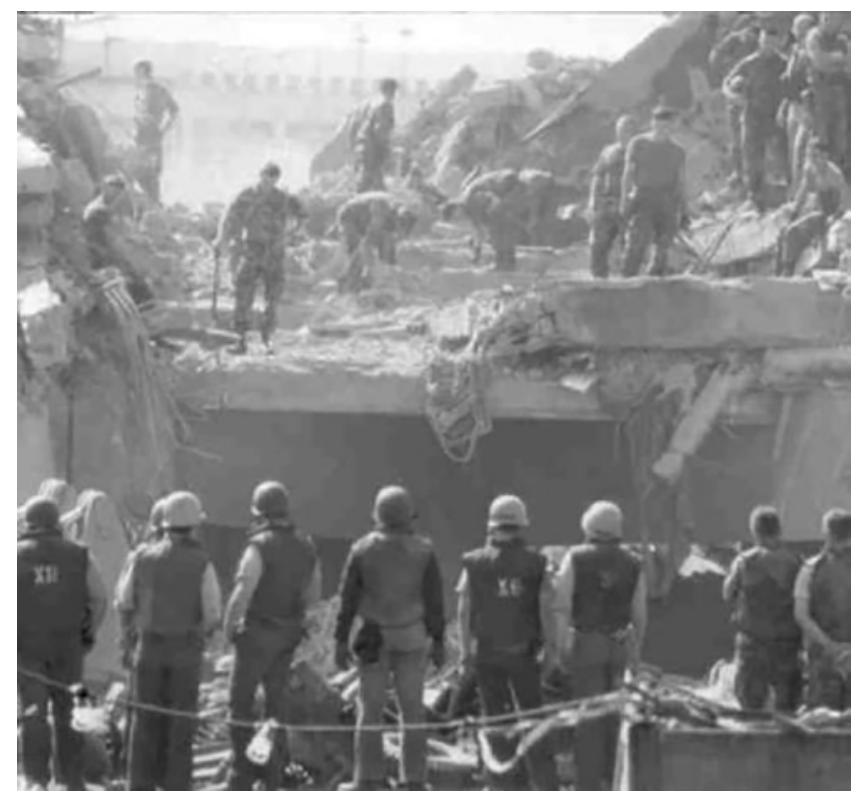

FIG. 1. US Marines survey the wreckage after searching for victims of the terrorist attack against the headquarters of the US troops of the multinational force that killed 241 American soldiers on October 23, 1983 , in Beirut, Lebanon.

cal assets of the MAU Service Support Group (MSSG) were organized into two triage teams. Additional medical support was mobilized from afloat units and rapidly transported ashore. A flight surgeon and 6 corpsmen were immediately dispatched to the shore from the USS Iwo Jima to help facilitate evacuation of survivors. As wounded were recovered from the rubble, they were immediately evaluated. A small number of wounded, based upon unreported criteria, were taken to local civilian hospitals and the Italian military field hospital as the situation unfolded, but essentially all other wounded were transported by helicopter to the USS Iwo Jima LPH-2 (amphibious helicopter platform), which served as the primary casualty receiving and treatment ship, where necessary resuscitation and surgery were accomplished.

The Mass Casualty Plan called for immediate evacuation of surviving personnel by helicopter to the USS Iwo Jima LPH-2, equipped with two operating rooms, an intensive care unit for two patients, a small ward and potential rack space for up to 100 wounded, and an x-ray suite. The ship possessed neither blood bank nor CT capability. Ventilator capacity was not tested, as operative patients were extubated after surgery. Ship medical officers had completed an approximately 10-day combat casualty care course prior to deployment, in addition to their specialtyspecific training. Within 90 minutes, 65 critically injured servicemen were received by helicopter from the shore upon the deck of the USS Iwo Jima. The wounded arrived on stretchers and were carried by nonmedical members of the ship's crew who had undergone training in stretcher bearing. They were brought down the aircraft elevator, to the hangar bay, where supplies had been pre-positioned (Fig. 2).

Each patient then underwent intravenous (IV) fluid in- 
fusion, Foley catheter placement, and blood pressure monitoring every 10 minutes by the ship's crew who had been trained in sphygmomanometry. Other members of the ship's personnel had been trained as scribes. One scribe was available for each of the wounded to record all appropriate data for that patient, to provide solace, and to alert the ship's doctor of any changes.

\section{Military Triage}

The wounded were triaged according to standard protocol at the time. ${ }^{20,21}$ The most severely wounded, as determined by physiological parameters and physician assessment, were taken by elevator up to the medical department. Abdominal, chest, and limb surgeries were performed by the attached general and orthopedic surgeons, and debridement of a skull fracture was performed by the ship's medical officer. ${ }^{10}$ The two laparotomies and the cranial procedure were completed within 12 hours of the event.

There were no walking wounded. There was one death aboard the USS Iwo Jima resulting from severe crush injuries. Survivors triaged with severe injuries requiring urgent surgery were designated for transfer to the nearby British military hospital in Akrotiri, Cyprus. Additionally, 14 patients were transferred to local Beirut hospitals, where neurosurgical capability was present. Six of the neurological patients considered "immediate" underwent craniectomy or craniotomy. In 5 of 6 patients, surgery was performed within the first 24 hours. ${ }^{19}$ Patients in the second category were triaged as less severe injuries and were deemed appropriate for transfer to Germany, a 5-hour flight.

The more critical group of patients, who should have gone to Akrotiri, was sent to Germany, and the less critical group, initially planned for Germany, was sent to Akrotiri. This error, thought not to have resulted in any deaths, occurred when a senior-ranked Air Force officer delivered emotionally charged and rushed orders overriding plans established by the ship's medical officer. By 17:00 on the day of the mass casualty event, all of the wounded had been treated on the ship and were evacuated except for the postoperative patients.

Support from the Royal Air Force proved vital. Aeromedical evacuation aircraft of the US Air Force, US Navy, and Royal Air Force conducted the evacuation of the surviving wounded to locations in Beirut, Cyprus, Germany, and Italy, where there had been a total mobilization of all major medical treatment facilities. Following definitive medical treatment at these overseas facilities, patients were returned to hospitals in the US as their conditions permitted.

Coincidentally, Senator Humphreys, chairman of the Preparedness Committee and a corpsman in the Korean War, witnessed the evaluation and care of the wounded in the hangar bay of the USS Iwo Jima. He commented that he had never seen such a well-executed evolution. The successful evolution was the result of meticulous preparation, including training of not only the medical personnel but also volunteers from the ship's company, frequent drilling with other shipboard units, coordination of resources throughout the ship, the presence of a meticulous senior enlisted man who carefully registered each of the wound-

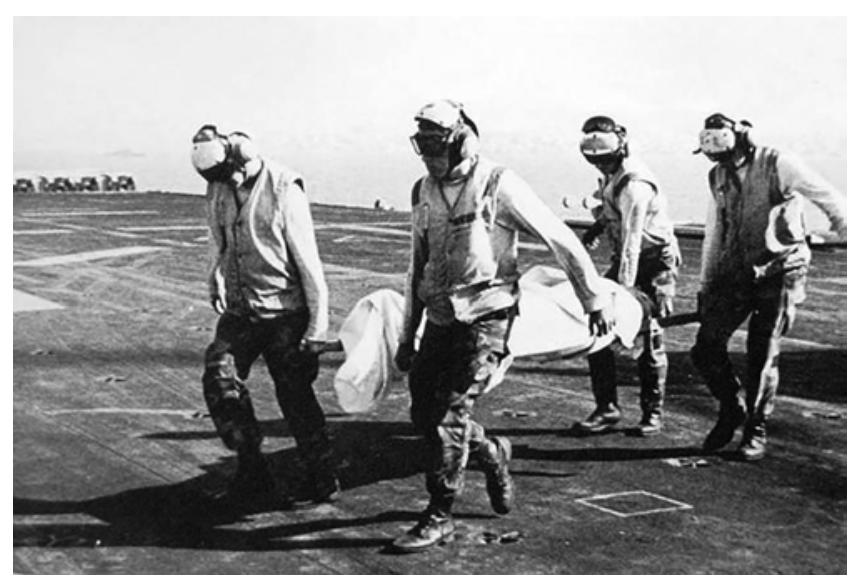

FIG. 2. Cargo personnel transport an injured soldier.

ed, the presence of trained security forces, and a drilled and functioning communication system.

\section{Lessons Learned in Mass Casualty Preparedness}

Training involved an understanding of the kinds of injuries that could be received and how they would be treated. Physician training was accomplished through combat casualty care courses undertaken prior to deployment. Onboard the ship, all of the corpsmen were trained for approximately 3 hours a day on the treatment of casualties. In addition, the captain of the ship was approached to permit the training of nonmedical crew in terms of stretcher bearing, of nonmedical staff in taking blood pressure, and of nonmedical persons in the function of scribes. Training was also accomplished through fleet-wide mass casualty events. Mock wounded were brought by helicopter to the Iwo Jima and the entire mass casualty event rehearsed every other week. Finally, as our troops were subject to constant sniper fire and other small explosives, the ship received a constant influx of wounded over the month prior to the mass casualty event. On the day of the explosion, all medical and nonmedical people knew their places and stood ready to perform their duty without instruction (Figs. 3-5). Consequently, the duties were carried out with relative quiet and no chaos. Such extensive training may not be practical in the civilian setting, but the underlying principle of preparation should be an emphasis for medical centers across the world. From a neurosurgical standpoint, participation in mass casualty exercises would be of benefit in both community and academic centers, as preparation and a sense of competence have been identified as protective psychological factors for participants in disaster work. ${ }^{6}$ Polytrauma experienced by victims of mass casualty events will inevitably require multidisciplinary care that extends across a variety of surgical specialties, including neurosurgery.

\section{Pre-Positioning of Supplies}

Upon arrival in Beirut, the ship's medical officer performed a complete survey of all medical supplies. Initial supply inventory was grossly inadequate to accommodate 


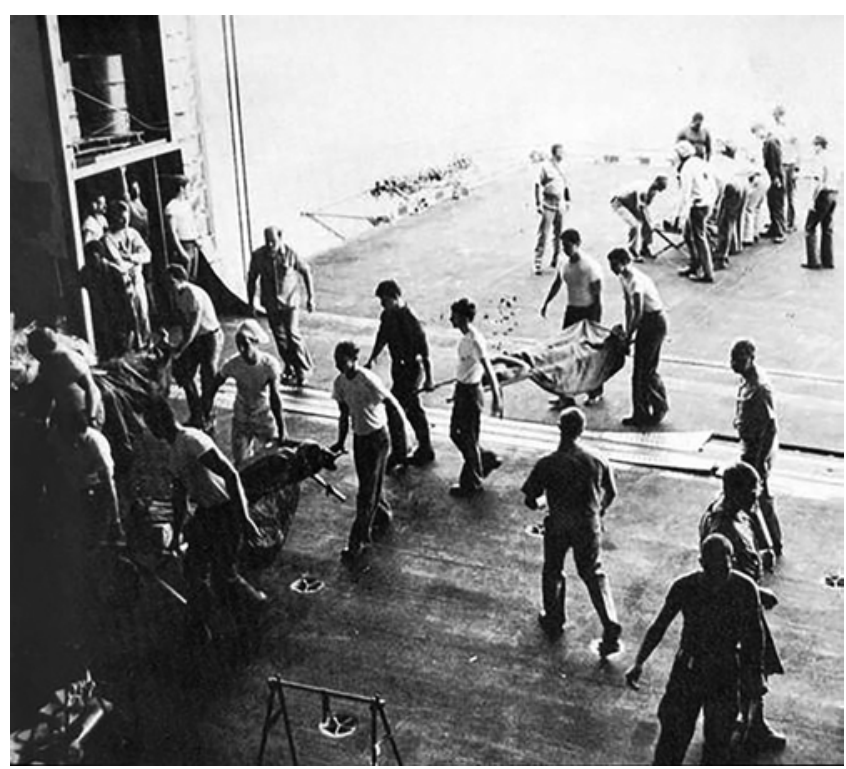

FIG. 3. Injured Marines await transfer from the flight deck to the hangar bay triage area.

a mass casualty event. Within the first week, therefore, adequate IV fluids, surgical supplies, and other medical supplies were ordered to accommodate 100 critically wounded troops. The pre-positioned supplies in the hangar bay facilitated rapid treatment of the wounded. Medical corpsmen were able to procure all of the medical equipment necessary to evaluate, monitor, and hydrate the wounded. Thus, stretchers, IV fluids, IV poles, Foley catheters, wristbands, patient charts, pens, blood pressure monitors, and extra stretchers were all carefully pre-positioned and immediately accessible. In the military setting, contingency plans exist for such scenarios; however, in the civilian setting, maintaining an equal standard may be difficult to achieve. It is a recommendation that clear channels of communication exist so that resource availability can be quickly ascertained and proper mechanisms of allocation can be executed.

\section{Establishing Triage Space}

Having adequate space to accomplish the evaluation of the critically wounded patients was imperative. The aviation officer had immediately moved all of the aircraft out of the hangar bay, making almost the entire hangar bay available for the placement of 65 stretchers in long lines. This greatly facilitated the management of these patients. There was ample space for ingress and egress of stretcher bearers, and the ability of one or two physicians to continually move up and down the lines of wounded to monitor the medical stability of each patient. Triage category location was understood by all healthcare providers.

\section{Drilling With Other Units}

Training was performed not only on the Iwo Jima but upon the other ships and in coordination with the Iwo Jima. Therefore, during mass casualty drills within the fleet, medical personnel traveled by helicopter with the

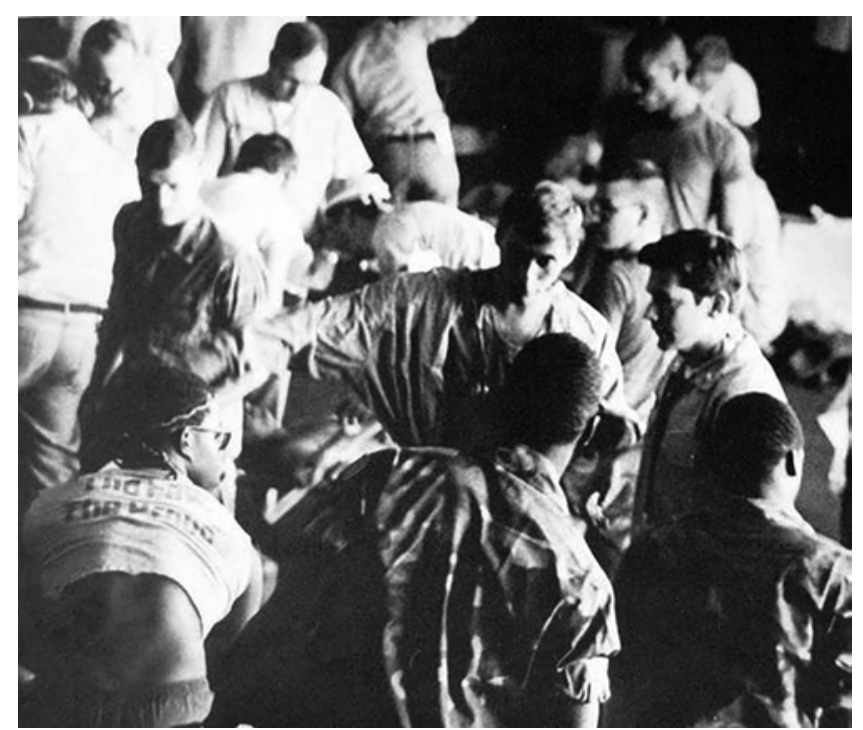

FIG. 4. The senior author confers with a surgical team doctor.

mock wounded to the USS Iwo Jima and participated in the coordinated mass casualty event drill. This increased the level of coordination within the fleet. Collaboration with emergency and trauma services is critical. ${ }^{4}$

\section{Registration of the Wounded}

Registration was accomplished by the senior chief of the medical department aboard the USS Iwo Jima. The accuracy and completeness of this record became a critical aspect of the care for these patients; the ability to know precisely who was wounded, how severely, and the location of that patient was of the utmost importance, not only for military commanders but also for the patients' families at home. There are a multitude of triage scoring systems utilized that have proven predictive values. ${ }^{13,22}$ Importantly, hospital systems and emergency personnel should have familiarity with these scoring systems, with preferential selection of one or a few of these systems to be implemented within a given geographic region to optimize communication in the event of a mass casualty scenario.

\section{Security}

Security was handled by the master-at-arms. Each of the wounded was inspected for the presence of arms and explosive devices. The master-at-arms was available in case of infiltration among the wounded by a terrorist. The master-at-arms was important for crowd control, handling of any weapons, and also being available to assist with any patient psychosis or unusual combative behavior. It is of the upmost importance that all healthcare providers remain safe during these events. Specialty providers should not be subjected to unnecessary risk and should remain in safe zones throughout the duration of these events.

\section{Communication Systems}

In any catastrophic event, there is a tendency for confusion, adrenaline, confusion of orders, and mistakes. The 


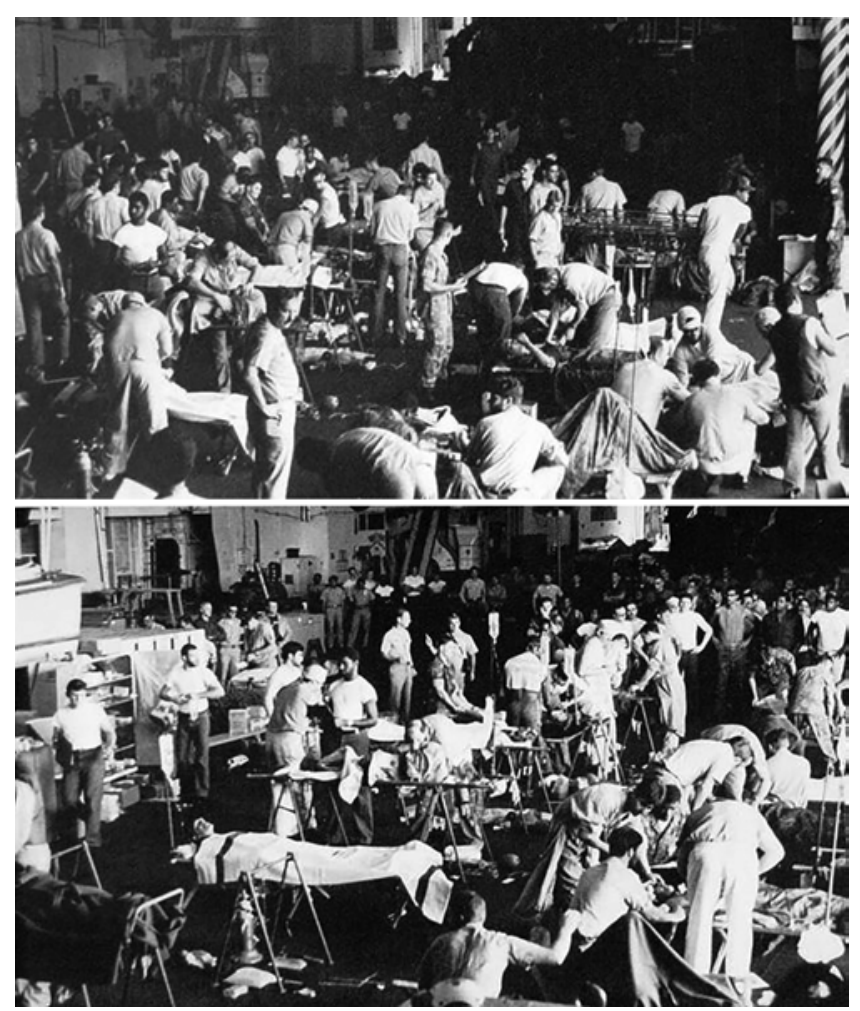

FIG. 5. Though it appears to be massive confusion, it was not. Each crew member knew and performed a specific role.

presence of clear communication between the superior officer deployed and the senior medical staff was critical. An auxiliary communication system had been established, although it was not necessary on this day. It is important for the medical staff, the hospital administrator, and the battle commander or a civic commander-in-chief to have established a relationship of communication in advance so that the appropriate directives can be made. Although communications within the ship were exemplary, they were not without incident. The delay of transport ships for evacuation of the wounded from the airport was not well communicated to the medical staff. While this did not result in any mortality, it did delay the evacuation of the wounded to the most nearby hospital in Cyprus. Discussion between the senior medical officer and the fleet commander may have resulted in a more expeditious evacuation of wounded to Cyprus by the British. Chains of command are critical for the reduction of these types of errors and are integral parts of mass casualty plans instituted across civilian and military systems.

\section{Discussion}

War and neurosurgical understanding have shared a reciprocal relationship that extends millennia. ${ }^{8}$ There is no debate that mass casualty situations are better handled by the prepared provider and facility. ${ }^{9}$ Much of the evidence supporting current triage protocols has been gathered from database review of events that occurred in resourcerich cities, where "over-triage" was not only permissible but preferred, a notable difference from many battlefield scenarios. ${ }^{22}$ And while there has been keen interest in standardization of triage techniques and nomenclature, the greatest risk to the mass casualty patient is the lack of adequate resources. ${ }^{14}$ By this it is meant that the patient is potentially at risk of needing care by a provider who is otherwise occupied; medication that has been consumed by the preceding patient(s); or treatment or evaluation by services that have been spent or are otherwise occupied, disallowing timely assessment or intervention. Yet, except for the rarest of situations, there are assets available if they can be identified and transport can be provided.

The important role of the neurosurgeon in the mass casualty event can be well illustrated by experiences in Kandahar, Afghanistan. In Kandahar, the debate often raged over stabilization versus definitive operative care. Notably, the example of spinal stabilization was a major point of contention: Kandahar Airfield Role 3 Multinational Military Medical Unit featured 4 operating rooms, though casualties would sometimes arrive in groups of 8 , 12 , or even 20 . Thus, consuming a room to provide definitive stabilization risked denying incoming casualties access to lifesaving operative care. It proved valuable to stabilize patients, often including decompressive surgery in the previously mentioned spinal injury patients, and to then expedite their transit to Landstuhl, Germany, or Walter Reed National Military Medical Center, for example, for definitive care. ${ }^{3}$

The neurosurgeon should be an active participant in the organization, training, and execution of mass casualty events. Blast injuries and gunshot wounds comprise a significant proportion of injuries in mass casualty events. Most events involve the use of explosive devices that result in a blast injury from pressure waves, which lead to significant head, lung, and abdominal trauma. ${ }^{12}$ Common injuries include concussion, ophthalmic injury, skull fracture, and subdural hematoma. Rignault and Deligny described the terrorist bombings in Paris from 1985 to 1986 and found head and neck injuries in $19.3 \% .^{18}$ Head and neck injuries were found in $48 \%$ of those injured in the Oklahoma City bombing, including 35 of the 83 hospitalized patients. ${ }^{15}$ Secondary blast injury results from the dissipation of shrapnel, leading to significant neurological injury in the form of penetrating brain trauma and peripheral nerve injury. A number of these patients will need debridement, evacuation, grafting, and repair by neurosurgeons. The large amount of peripheral nerve injury from both explosive devices and gunshot wounds requires neurolysis and primary suture repair with grafting in some cases. ${ }^{5}$ Importantly, explosions cause structural collapse and the fragmentation of buildings and vehicles. ${ }^{7}$ Structural collapses secondary to explosives lead to an intracranial injury rate of $10 \%$ and a crush injury rate of $12 \%$. Moreover, $8 \%$ in confined-space explosions suffer intracranial pathology. ${ }^{1}$ An algorithm for assessing evacuation priorities in headinjured patients requires immediate clinical assessment of level of consciousness. ${ }^{13}$ Neurosurgeons are expert in quick, accurate examination and must oversee training of those who will be determining these consequential Glasgow Coma Scale assessments. Neurosurgeons trained in endovascular techniques may be well suited to perform 
or teach new balloon occlusion techniques to mitigate exsanguinating hemorrhage in triage facilities such as shipboard.$^{17}$ In short, the rate of nerve, spine, and brain injury in these patients will likely be high, and the neurosurgeon has a wealth of experience in dealing with these injuries.

Modern real-time communication modalities, just-intime deliveries, and Internet or "app"-based capabilities will offer tools to the current neurosurgeon that were not available in $1983 .^{2}$ It is our contention that care of mass casualty patients need not be restricted to the coordination of events at a single facility. Communication through realtime informatics would allow command elements to divert patients as they leave a mass casualty scene. Through coordination of shared information, patients could be assigned to facilities that have resources available to provide much needed care. The lessons learned from the barracks bombing in Beirut should include the clear need for asset identification across the theater of interest. In the civilian world, that would include regional assets. University and level I trauma centers must exercise leadership in developing community or regional consensus as to the language, such as that utilized by our military and in establishing a Web-based trauma system, which can provide real-time information on available assets. ${ }^{23}$ Members of the command and control elements should be able to direct patients to the appropriate facility, as well as send vital information pertaining to inbound casualties. This creates a virtual receiving facility that disperses patients to those locations most capable of providing a maximum level of care and support. This proposed mass casualty dashboard would provide on-scene management teams the capacity to identify available beds, surgical capability, blood bank accessibility, imaging, and interventional support, as well as transit options, thus maximizing patient outcome through efficient and direct regulation of transport to endsupport facilities.

\section{Conclusions}

The authors suggest 8 points for successful mass casualty preparedness. First, a corps of medical personnel should be trained specifically to handle the kinds of injuries anticipated from a mass casualty event and should rehearse for one on a regular basis using mock-up patients. Neurosurgery staff should play an integral role in the training and planning process alongside other clinicians. Second, training of nurses, corpsmen, and nonmedical personnel is essential. In a large-scale evolution, nonmedical personnel are extremely useful for monitoring vital signs, working as scribes, being stretcher bearers, and running messages. Third, ample supplies should be stored in locations that are immediately accessible to the spaces in which mass casualty evaluations will be carried out. Fourth, a large space is necessary to accomplish the safe and effective evaluation and monitoring of mass casualties. This allows for relatively few medical personnel to oversee a large number of patients. Fifth, there should be planned strategies with hospital administrators, civic administrators, and chief medical personnel so that all are in reasonable agreement as to how evacuation of the wounded will be carried out. Sixth, extremely competent personnel should be enlisted to perform the meticulously detailed registration of each wounded patient. Seventh, security measures should be in place to prevent a catastrophe within the medical center. The mass casualty evolution should be carried out with relative quiet, each person knowing his/her place and instructed in his/her duty, with an intention to cultivate psychological resilience among the team. Finally, the senior figures of authority must exercise equanimities and, as such, dissuade the use of negative language or adrenalinebased decision-making.

Mass casualty events are very high-stress, high-visibility events, with a significant possibility for major errors that result from lack of communication and lack of planning. Any error may result in retrospective mischaracterization of events that might be harmful to the casualties, their families, the medical providers, and the institution providing the medical treatment.

\section{Acknowledgments}

Photographs (Figs. 1-5) were taken by Randy Gaddo and Al Sandrik. All photographs were taken by employees of the federal government while on duty.

\section{References}

1. Arnold JL, Tsai MC, Halpern P, Smithline H, Stok E, Ersoy G: Mass-casualty, terrorist bombings: epidemiological outcomes, resource utilization, and time course of emergency needs (Part I). Prehosp Disaster Med 18:220-234, 2003

2. Bachmann DJ, Jamison NK, Martin A, Delgado J, Kman NE: Emergency preparedness and disaster response: there's an app for that. Prehosp Disaster Med 30:486-490, 2015

3. Bell RS, Mossop CM, Dirks MS, Stephens FL, Mulligan L, Ecker R, et al: Early decompressive craniectomy for severe penetrating and closed head injury during wartime. Neurosurg Focus 28(5):E1, 2010

4. Biddinger PD, Baggish A, Harrington L, d'Hemecourt P, Hooley J, Jones J, et al: Be prepared-the Boston Marathon and mass-casualty events. N Engl J Med 368: 1958-1960, 2013

5. Birch R, Misra P, Stewart MP, Eardley WG, Ramasamy A, Brown K, et al: Nerve injuries sustained during warfare: part I-epidemiology. J Bone Joint Surg Br 94:523-528, 2012

6. Brooks S, Amlôt R, Rubin GJ, Greenberg N: Psychological resilience and post-traumatic growth in disaster-exposed organisations: overview of the literature. J R Army Med Corps [epub ahead of print], 2018

7. DePalma RG, Burris DG, Champion HR, Hodgson MJ: Blast injuries. N Engl J Med 352:1335-1342, 2005

8. Dowdy J, Pait TG: The influence of war on the development of neurosurgery. J Neurosurg 120:237-243, 2014

9. Frykberg ER: Triage: principles and practice. Scand J Surg 94:272-278, 2005

10. Frykberg ER, Hutton PM, Balzer RH Jr: Disaster in Beirut: an application of mass casualty principles. Mil Med 152:563-566, 1987

11. Frykberg ER, Tepas JJ III: Terrorist bombings. Lessons learned from Belfast to Beirut. Ann Surg 208:569-576, 1988

12. Katz E, Ofek B, Adler J, Abramowitz HB, Krausz MM: Primary blast injury after a bomb explosion in a civilian bus. Ann Surg 209:484-488, 1989

13. Knuth T, Letarte PB, Ling G, Moores LE, Rhee P, Tauber D, et al: Guidelines for the Field Management of Combat-Related Head Trauma. New York: Brain Trauma Foundation, 2005

14. Lerner EB, Schwartz RB, Coule PL, Weinstein ES, Cone DC, 
Hunt RC, et al: Mass casualty triage: an evaluation of the data and development of a proposed national guideline. Disaster Med Public Health Prep 2 (Suppl 1):S25-S34, 2008

15. Mallonee S, Shariat S, Stennies G, Waxweiler R, Hogan D, Jordan F: Physical injuries and fatalities resulting from the Oklahoma City bombing. JAMA 276:382-387, 1996

16. Osler W: Aequanimitas: With Other Addresses to Medical Students, Nurses and Practitioners of Medicine. Philadelphia: P Blakiston's Son \& Co, 1922

17. Rees P, Waller B, Buckley AM, Doran C, Bland S, Scott T, et al: REBOA at Role 2 Afloat: resuscitative endovascular balloon occlusion of the aorta as a bridge to damage control surgery in the military maritime setting. J R Army Med Corps 164:72-76, 2018

18. Rignault DP, Deligny MC: The 1986 terrorist bombing experience in Paris. Ann Surg 209:368-373, 1989

19. Scott BA, Fletcher JR, Pulliam MW, Harris RD: The Beirut terrorist bombing. Neurosurgery 18:107-110, 1986

20. US Department of Defense: Emergency War Surgery: First United States Revision of the Emergency War Surgery NATO Handbook. Washington, DC: US Government Printing Office, 1975

21. US Department of the Navy: Fleet Marine Force Manual (FMFM) 4-5. Washington, DC: US Government Printing Office, 1980

22. Vassallo J, Horne S, Smith JE: Triage and the Modified Phys- iological Triage Tool-24 (MPTT-24). J R Army Med Corps [epub ahead of print], 2018

23. Wiseman DB, Ellenbogen R, Shaffrey CI: Triage for the neurosurgeon. Neurosurg Focus 12(3):E5, 2002

\section{Disclosures}

Dr. Spiotta is a consultant for Penumbra, Minnetronix, and Cerenovus.

\section{Author Contributions}

Conception and design: all authors. Acquisition of data: Hubbard, Henderson Jr., Rosenbaum, Henderson Sr. Analysis and interpretation of data: Hubbard, Henderson Jr., Armonda, Spiotta, Henderson Sr. Drafting the article: Hubbard, Henderson Jr., Spiotta, Rosenbaum, Henderson Sr. Critically revising the article: Hubbard, Henderson Jr., Armonda, Spiotta, Henderson Sr. Reviewed submitted version of manuscript: all authors. Approved the final version of the manuscript on behalf of all authors: Hubbard.

\section{Correspondence}

Zachary S. Hubbard: Medical University of South Carolina, Charleston,SC.hubbardz@musc.edu. 